\title{
Analisis Kinerja Pembangkit Listrik Dual-Fuel Berbasis Gasifikasi Municipal Solid Waste
}

\author{
( Gede Suparsa Adnyana ${ }^{1)^{\star}}$, I Gusti Bagus Wijaya Kusuma1), \\ I Gusti Agung Kade Suriadi ${ }^{1)}$
}

\author{
1)Jurusan Teknik Mesin, Fakultas Teknik, Universitas Udayana \\ Kampus Bukit Jimbaran, Jalan Raya Kampus Unud Jimbaran Bali 80362 \\ Email: suparzaadnyana@ymail.com, igbwijayakusuma@unud.ac.id, gungsuriadi@yahoo.com
}

doi: https://doi.org/10.24843/METTEK.2019.v05.i01.p05

\begin{abstract}
Abstrak
Telah dilakukan penelitian tentang pengaruh dual-fuel hasil gasifikasi bahan bakar biomasa terhadap daya keluaran pada mesin diesel kapasitas $40 \mathrm{~kW}$. Penelitian ini bertujuan untuk mengetahui pengaruh aliran gas hasil gasifikasi biomasa sampah campuran perkotaan terhadap daya keluaran pada mesin diesel kapasitas $40 \mathrm{~kW}$. Pengukuran dilakukan dengan mengukur laju udara pembakaran bukaan $0 \%, 50 \%$ dan $100 \%$, laju alir syngas, konsumsi bahan bakar spesifik, daya yang dihasilkan dan beban listrik yang diberikan $0 \%, 10 \%, 20 \%, 30 \%, 40 \%, 50 \%, 60 \%, 70 \%, 80 \%, 90 \%$, $100 \%$. Data menunjukan bahwa penggunaan, dual-fuel menghasilkan daya keluaran yang lebih besar dibandingkan dan juga mengurangi penggunaan solar sebesar $53.25 \%$ dibandingkan single-fuel. Sedangkan dengan membandingkan konsumsi bahan bakar total antara Bukaan Penuh dan Setengah, Bukaan Setengah untuk menghasilkan daya yang sama dengan Bukaan Penuh pada rasio beban $100 \%$ yaitu $36.6 \mathrm{~kW}$ perlu melakukan pengoperasian lebih banyak 3.05 kali namun mampu mengurangi konsumsi bahan bakar total sejumlah $5.835 \mathrm{~kg} / \mathrm{Jam}$.
\end{abstract}

Kata kunci: Dual-fuel, Biomasa, MSW, Mesin Diesel, Syngas

\section{Abstract}

Research on the effect of dual-fuel biomass fuel gasification results on the output power of diesel engines with a capacity of $40 \mathrm{~kW}$. This study aims to determine the effect of gas flow from urban mixed biomass gasification results on the output power of diesel engines with a capacity of $40 \mathrm{~kW}$. Measurements were made by measuring the open air combustion rate of $0 \%, 50 \%$ and $100 \%$, syngas flow rate, specific fuel consumption, power generated and electrical loads given $0 \%, 10 \%, 20 \%, 30 \%, 40 \%$, $50 \%, 60 \%, 70 \%, 80 \%, 90 \%, 100 \%$. Data shows that the use of dual-fuel produces greater output power and also reduces diesel fuel use by $53.25 \%$ compared to singlefuel. Whereas by comparing the total fuel consumption between Full and Half Openings, Half Openings to produce the same power as Full Openings at a load ratio of $100 \%$, which is $36.6 \mathrm{~kW}$, it needs to do more operation 3.05 times but is able to reduce the total fuel consumption by $5,835 \mathrm{~kg} / \mathrm{hour}$.

Keywords: Dual-fuel, Biomass, MSW, Diesel engines, Syngas

${ }^{*}$ Penulis korespondensi, HP : 081246962175

Email : suparzaadnyana@ymail.com 


\section{PENDAHULUAN}

Laju konsumsi energi global cenderung mengalami peningkatan setiap tahun. Pada tahun 2014, pemenuhan kebutuhan energi global sebesar 12.928,4million tonnes oilequivalent masih didominasi oleh bahan bakar fosil. Pemanfaatan sumber energi terbarukan dalam pemenuhan kebutuhan energi global perlu ditingkatkan. Salah satu teknologi yang dapat digunakan untuk pembangkitan energi terbarukan adalah dari biomassa dengan cara diproses secara gasifikasi. Pemanfaatan $M S W$ sebagai umpan gasifikasi juga dapat mengurangi jumlah limbah sampah sekaligus menambah nilai ekonomis dari limbah sampah. Dengan diterapkannya teknologi ini, ketergantungan terhadap bahan bakar fosil dapat dikurangi. Lebih dari itu, pengembangan teknologi ini hingga skala nasional berpotensi mengatasi ketidakmerataan distribusi energi listrik pada berbagai daerah terpencil di Indonesia. Oleh sebab itu perlu diteliti pengaruh pemakaian gasproduser hasil gasifikasi limbah padat kota Denpasar terhadap kinerja pembangkit listrik diesel, dengan memvariasikan laju alir udara pembakaran dan beban listrik.

\section{METODE}

Pengambilan data dilakukan dengan melakukan pengujian kinerja pada mesin diesel single-fuel yang digunakan sebagai acuan untuk mencari data pada saat mesin dual-fuel. Pada saat mode single-fuel dilakukan pengamatan untuk memperoleh data berupa konsumsi bahan bakar solar, daya keluaran yang dihasilkan dengan valve inlet udara penuh dengan rasio beban $0 \%$ hingga $100 \%$. Dan pada mode dual-fuel data yang dicari adalah konsumsi bahan bakar solar, laju alir gas produser, daya genset, dan konsumsi biomasa MSW pada bukaan valve udara $50 \%$ dan $100 \%$ dengan pembebanan listrik $0 \%$ hingga 100\%. Sehingga diperoleh perbandingan antara mode single-fuel dan dual-fuel untuk menentukan penghematan bahan bakar dan daya output yang lebih baik.

\section{HASIL DAN PEMBAHASAN}

Berdasarkan pengujian pada fase Dual-fuel diperoleh tabel data konsumsi bahan bakar baik penggunaan bahan bakar solar maupun biomasa dengan beban $0 \%, 10 \%, 20 \%, 30 \%$, $40 \%, 50 \%, 60 \%, 70 \%, 80 \%, 90 \%, 100 \%$ yang disertai dengan laju alir dari syngas dan daya mesin diesel yang dihasilkan, sehingga dapat diketahui penghematan solar dan daya output mesin diesel pada fase dual-fuel dari biomasa municipal solid waste. Dari tabel tersebut dibentuk ke dalam sekumpulan grafik untuk mengetahui perbandingan dan hubungan dari masing-masing data.

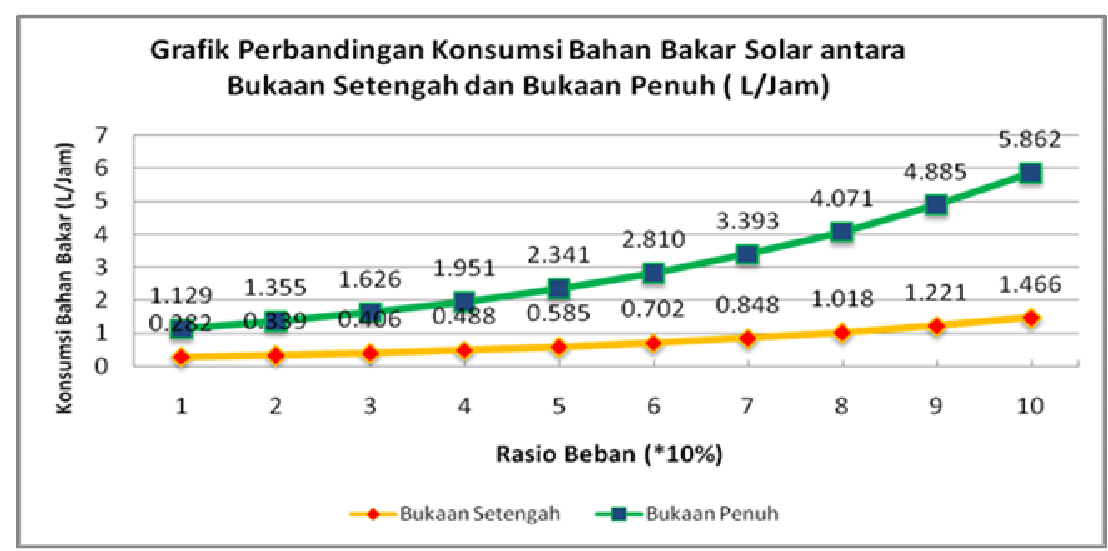

Grafik 1. Perbandingan Konsumsi Bahan Bakar Solar antara Bukaan Setengah dan Bukaan Penuh 
Diagram diatas menunjukkan bahwa konsumsi bahan bakar solar mengalami kenaikan seiring dengan penambahan rasio beban listrik baik pada Bukaan Setengah maupun Bukaan Penuh, namun konsumsi bahan bakar solar pada saat Bukaan Penuh lebih besar dibandingkan Bukaan Setengah. Untuk mengetahui konsumsi solar didapatkan melaui persamaan sebagai berikut :

$$
\begin{gathered}
\text { Konsumsi Solar I }=16.318_{\mathrm{kg}}-16.278_{\mathrm{kg}}=0.040^{\mathrm{kg}} / 10 \mathrm{menit} \\
\text { Konsumsi Solar II }=16.273_{\mathrm{kg}}-16.271_{\mathrm{kg}}=0.042^{\mathrm{kg}} / 10 \mathrm{menit} \\
\text { Rata }- \text { rata Konsumsi Solar }=(0.040+0.042): 2 \times 6=0.248^{\mathrm{kg}} / \mathrm{Jam} \\
\text { Sehingga dikonversikan } L / \mathrm{Jam}=(0.248: 0.878)=0.282^{\mathrm{L}} / \mathrm{Jam}
\end{gathered}
$$

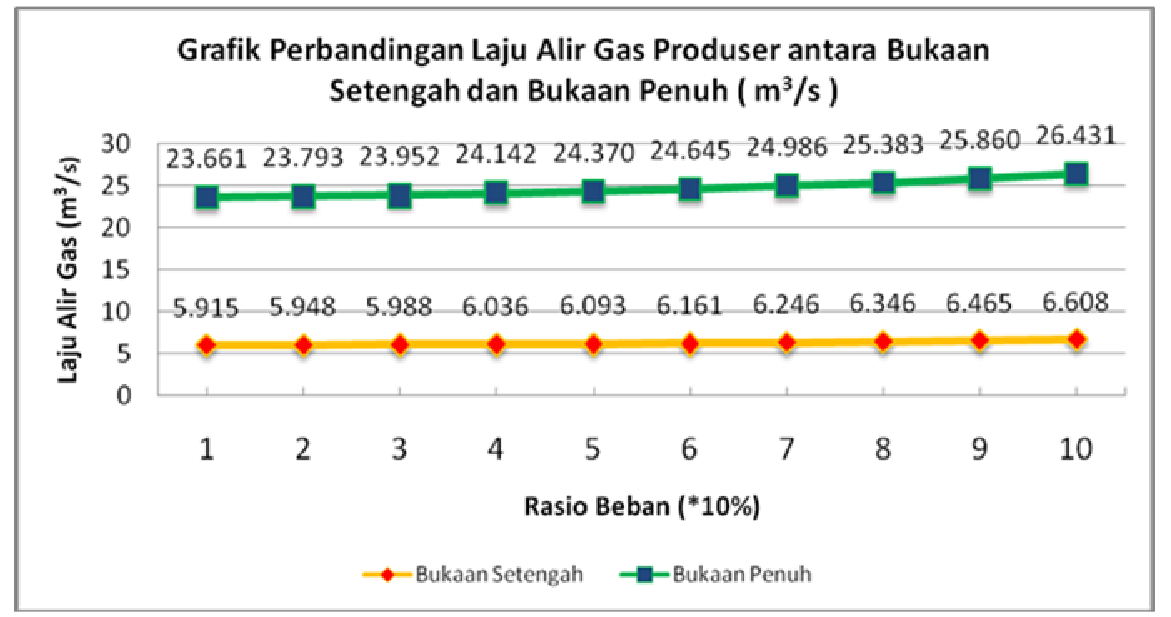

Grafik 2. Perbandingan Laju Alir Gas Produser antara Bukaan Setengah dan Bukaan Penuh

Gambar diagram diatas menunjukkan bahwa laju alir gas produser mengalami peningkatan seiring dengan penambahan rasio beban listrik yang dilakukan baik pada saat Bukaan Setengah maupun Bukaan Penuh, namun laju gas produser yang dihasilkan pada saat Bukaan Penuh lebih besar dibandingkan Bukaan Setengah. Untuk mengetahui laju alir gas produser dapat diketahui menggunakan rumus dibawah ini :

$\dot{\boldsymbol{m}}=\rho \cdot v \cdot A$

$\rho=1.2^{\mathrm{kg}} / \mathrm{m}^{3} \quad v=m / \mathrm{s}=2.11 \mathrm{~m} / 0.21 \mathrm{~s}=10.06 \mathrm{~m} / \mathrm{s}$

$A=\pi \cdot r^{2}=3.14 \cdot 0.0125^{2}=0.00049 m^{2}$

$\dot{m}=1.2^{\mathrm{kg}} / \mathrm{m}^{3} \cdot 10.06 \mathrm{~m} / \mathrm{s} \cdot 0.00049 \mathrm{~m}^{2}=5.915^{\mathrm{kg}} / \mathrm{s}$ 


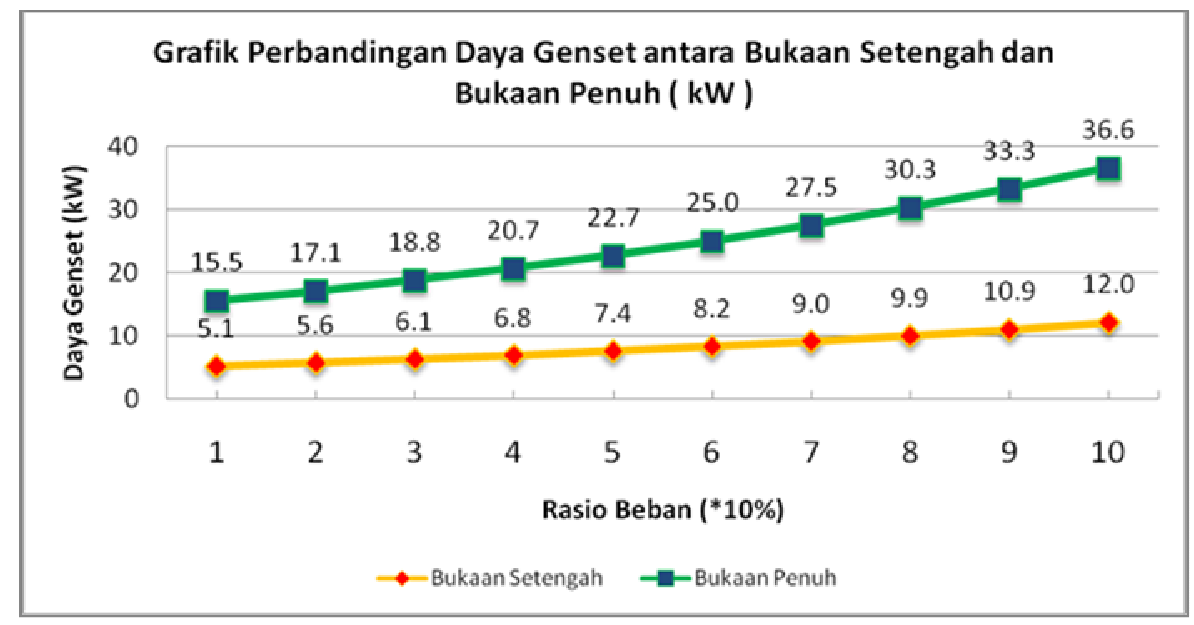

Grafik 3. Perbandingan Daya Genset antara Bukaan Setengah dan Bukaan Penuh

Diagram 3 menunjukkan dengan peningkatan rasio beban listrik maka daya genset yang dihasilkan juga mengalami peningkatan baik pada saat Bukaan Setengah maupun Bukaan Penuh, akan tetapi daya genset yang lebih besar dihasilkan pada saat Bukaan Penuh.

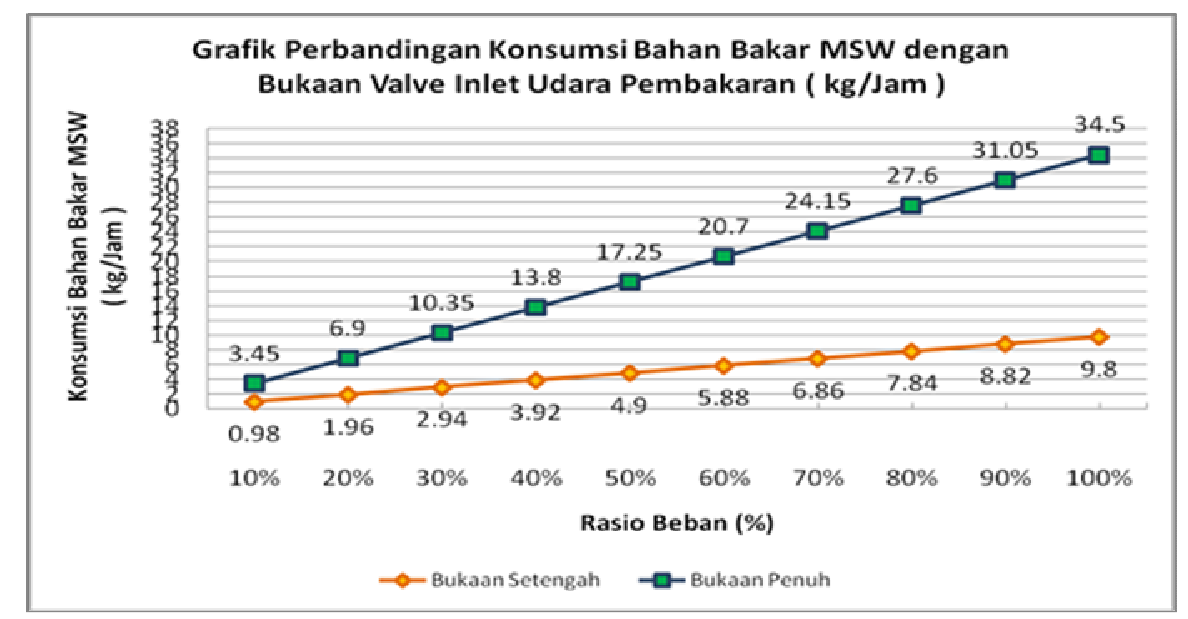

Grafik 4. Perbandingan Konsumsi MSW Bukaan Setengah dan Bukaan Penuh

Konsumsi bahan bakar mengalami peningkatan seiring dengan meningkatnya rasio beban yang diberikan. Pada Bukaan Penuh memerlukan lebih banyak bahan bakar $M S W$ dibandingkan pada Bukaan Setengah $\left({ }^{\mathrm{kg}} / \mathrm{Jam}\right)$.

Data Konsumsi Bahan Bakar Biomassa $M S W$ diperoleh menggunakan persamaan :

\section{Komsumsi Bahan Bakar Biomassa = (Biomassa yang digunakan (kg) : Waktu operasi genset (menit))}

Perhitungan pada Bukaan Setengah :

Komsumsi Biomassa $=(23 \mathrm{~kg}: 140$ menit $)=0.164^{\mathrm{kg}} / \mathrm{menit} \rightarrow 9.8^{\mathrm{kg}} / \mathrm{jam}$

Perhitungan pada Bukaan Penuh :

Komsumsi Biomassa $=(23 \mathrm{~kg}: 40$ menit $)=0.575 \mathrm{~kg} / \mathrm{menit} \rightarrow 34.5^{\mathrm{kg}} / \mathrm{jam}$ 


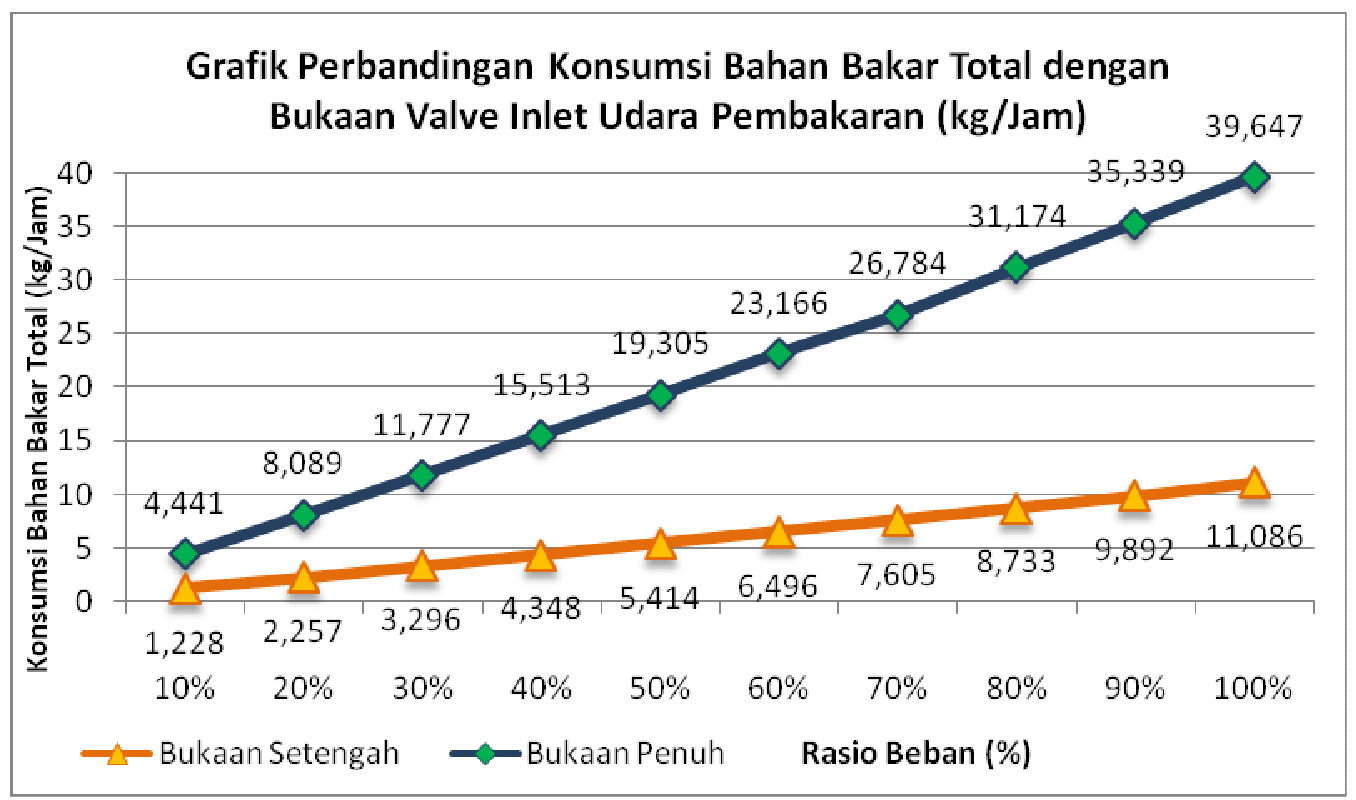

Grafik 5. Grafik Perbandingan Konsumsi Bahan Bakar Total dengan Bukaan Valve Inlet Udara Pembakaran

Grafik menunjukkan pada Bukaan Penuh memerlukan konsumsi bahan bakar total hasil penjumlahan solar dan biomassa lebih besar dibandingkan dengan Bukaan Setengah. Data konsumsi bahan bakar total dihitung dengan persamaan :

Konsumsi Bahan Bakar Total = BB Solar $(\mathrm{kg})+$ BB Biomassa $(\mathrm{kg})$

Contoh perhitungan pada Bukaan Setengah dengan Rasio Beban 100\% :

$$
\text { Konsumsi BB } B_{\text {total }}=1,286(\mathrm{~kg} / \mathrm{Jam})+9,8(\mathrm{~kg} / \mathrm{Jam})=11,086(\mathrm{~kg} / \mathrm{Jam})
$$

Contoh perhitungan pada Bukaan Penuh dengan Rasio Beban 100\%:

$$
\text { Konsumsi BB } B_{\text {total }}=5,147(\mathrm{~kg} / \mathrm{Jam})+34,5(\mathrm{~kg} / \mathrm{Jam})=39,647(\mathrm{~kg} / \mathrm{Jam})
$$

Telah diketahui pada tabel 4.2. bahwa pada Bukaan Penuh rasio beban 100\% mampu menghasilkan daya sebesar $36.6 \mathrm{~kW}$ dan pada Bukaan Setengah dengan rasio beban yang sama menghasilkan $12 \mathrm{~kW}$.

Dengan data hasil konsumsi bahan bakar total yang ditampilkan pada grafik 4.5. kita dapat mengetahui penghematan atau selisih penggunaan bahan bakar total dengan melakukan perbandingan daya yang dihasilkan pada persamaan dibawah :

\section{Daya Bukaan Penuh : Daya Bukaan Setengah$$
36.6 \mathrm{~kW}: 12 \mathrm{~kW}=3.05: 1
$$

Sehingga dari hasil tersebut diketahui untuk mencapai daya yang sama seperti pada Bukaan Penuh pada rasio beban 100\%, Bukaan Setengah perlu melakukan 3.05 kali pengoperasian sehingga dapat memenuhi kebutuhan daya $36.6 \mathrm{~kW}$. 
Dari pernyataan diatas selisih konsumsi bahan bakar total yang digunakan dapat dihitung dengan perhitungan :

\section{( Konsumsi Bahan Bakar Bukaan Penuh - (Perbandingan Daya x Konsumsi Bahan Bakar Bukaan Setengah))}

(39.647- ( $3.05 \times 11.086))$

$=(39.647-33.812)$

$=5.835^{\mathrm{kg}} / \mathrm{Jam}$

Dari perhitungan diatas Bukaan Setengah untuk menghasilkan daya yang sama dengan Bukaan Penuh yaitu $36.6 \mathrm{~kW}$ perlu melakukan pengoperasian lebih banyak 3.05 kali namun mampu mengurangi konsumsi bahan bakar total sejumlah $5.835 \mathrm{~kg} / \mathrm{Jam}$.

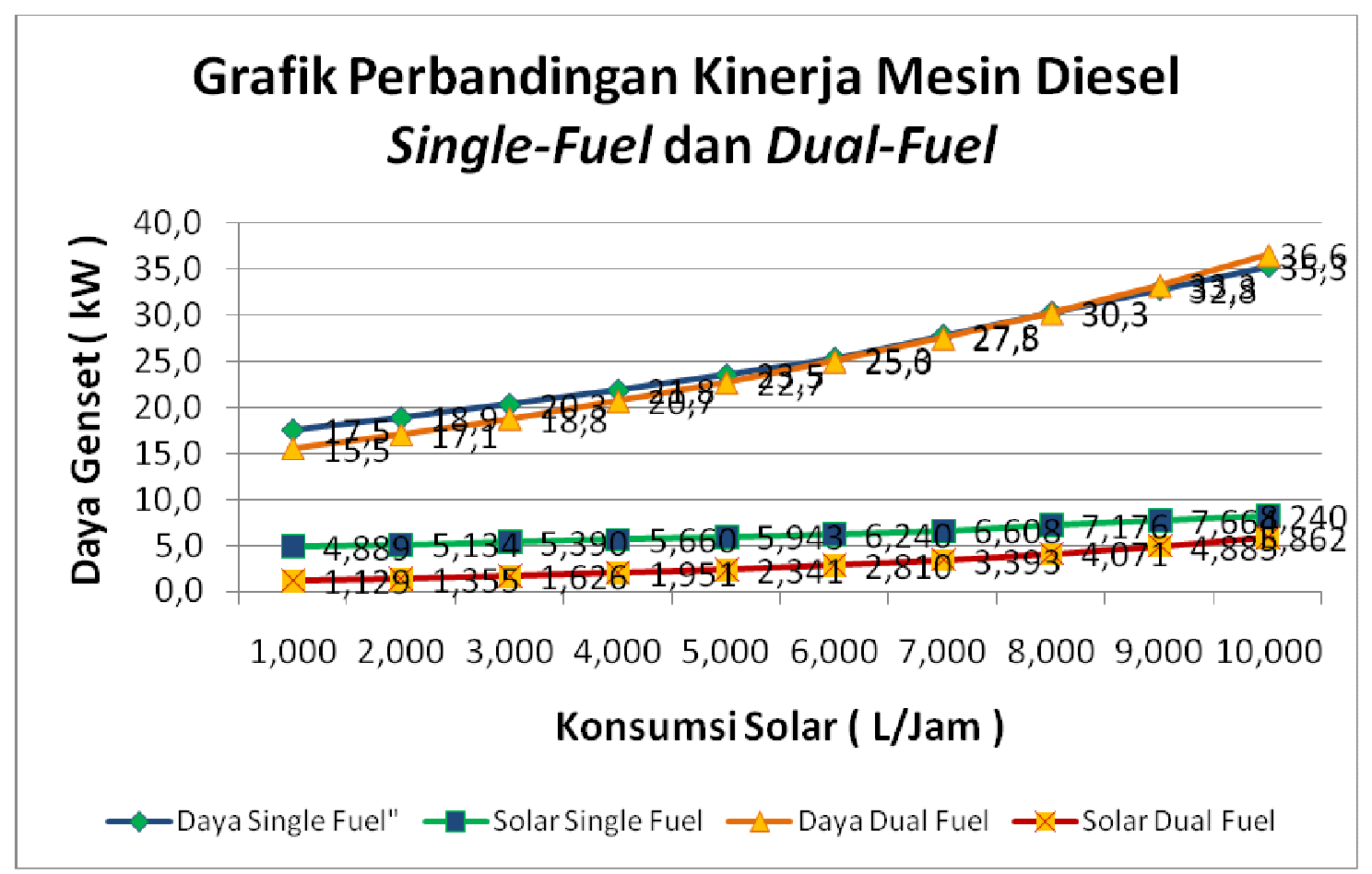

Grafik 6. Grafik Perbandingan Kinerja Mesin Single-Fuel dan Dual-Fuel

Pada diagram diatas menunjukkan pada Kinerja Mesin Diesel Dual-Fuel menghasilkan daya genset sebesar $36.6 \mathrm{~kW}$ dan memerlukan konsumsi solar sebanyak 5.862 L/Jam sedangkan Single-Fuel menghasilkan daya genset sebesar $35.3 \mathrm{~kW}$ dan memerlukan konsumsi solar sebanyak $8.240 \mathrm{~L} / \mathrm{Jam}$ pada bukaan valve inlet udara pembakaran penuh dengan rasio beban $100 \%$. Sehingga dari data diatas dapat diperoleh presentase substitusi gas yang menunjukkan hasil pengurangan solar akibat gasifikasi biomassa $M S W$ dengan menggunakan persamaan sebagai berikut :

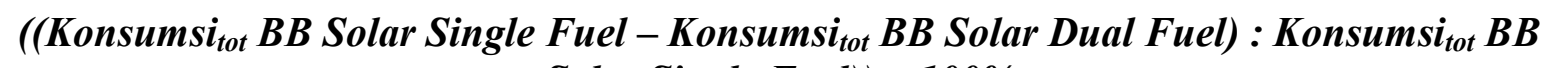
Solar Single Fuel)) $x$ 100\%

$$
=((62.944-29.423): 62.944)) \times 100 \%=53.25 \%
$$




\section{SIMPULAN}

Menurut hasil dari penelitian yang telah dilakukan, mampu disimpulkan bahwa pengaturan atau konfigurasi pada inlet udara amat mempengaruhi kinerja mesin diesel untuk mencapai daya maksimal dengan penghematan bahan bakar diesel seperti yang diinginkan. Hal ini dibuktikan dengan data tabel yang menunjukkan dengan mode dual-fuel, syngas hasil gasifikasi $M S W$ mampu mengurangi penggunaan solar sebanyak 2,378 L/Hour dan terjadi peningkatan daya sebesar $1,3 \mathrm{~kW}$. Pellet $M S W$ mampu menghemat bahan bakar sebesar $53.25 \%$ dibandingan pada mode Single-fuel. Sedangkan dengan membandingkan konsumsi bahan bakar total antara Bukaan Penuh dan Setengah, Bukaan Setengah untuk menghasilkan daya yang sama dengan Bukaan Penuh pada rasio beban $100 \%$ yaitu $36.6 \mathrm{~kW}$ perlu melakukan pengoperasian lebih banyak 3.05 kali namun mampu mengurangi konsumsi bahan bakar total sejumlah $5.835 \mathrm{~kg} / \mathrm{Jam}$.

\section{DAFTAR PUSTAKA}

[1] All Power Labs, 2015, "The Five Processes of Gasification".

[2] Arif R Saleh dkk. 2015, "Perancangan Sistem Gasifikasi Biomassa Pelepah Kelapa Sawit Pada Mesin Diesel $10 \mathrm{~kW}$ ”.

[3] BPS (Badan Pusat Statistik), 2015, "Produksi Padi Tahun 2015 Diperkirakan Naik $6,64 \% "$.

[4] Bridgwater,T. 2006, "Review Biomass for energy", Journal of the Science of Foodand Agriculture, vol. 86 pp.1755-1768,Bio-Energy Research Group, Aston University, Birmingham.

[5] Damanhuri E, 2010. “Teknologi Dan Pengelolaan Sampah Kota di Indonesia”.

[6] Dian M Novita dan Damanhuri E, 2010. "Perhitungan Nilai Kalor Berdasarkan Komposisi Dan Karakteristik Sampah Perkotaan Di Indonesia Dalam Konsep Waste To Energy".

[7] Endang Suhendi, 2016, "Pengaruh Laju Alir Udara dan Waktu Proses Gasifikasi Terhadap Gas Producer Limbah Tangkai Daun Tembakau Menggunakan Gasifier Tipe Downdraft".

[8] Florian W , 2014, "Pemanfaatan Limbah Sabut Kelapa dan Pengaruhnya Terhadap Variasi Beban Motor Listrik Dengan Menggunakan Alat Gasifikasi Tipe Downdraft".

[9] Hidayat A, 2014. "Karakterisasi Proses Gasifikasi Biomassa pada Reaktor Downdraft Sistem Batch dengan Variasi Air -Fuel Ratio (AFR) dan Ukuran Biomassa".

[10] Siregar, Kiman. 2015. "M.K. Pengantar Teknologi Pertanian"

[11] Laode M Firman, 2018. "Perancangan Sistem Pembangkit Listrik Tenaga Biomassa Berbahan Bakar Bambu Kapasitas 700kW Di Kepulauan X.

[12] Marcic, Milan. 2016. Downdraft Gasifier Diagram

[13] Murfihenni, W.dan Hermawan, D. 2014. "Pengolahan Bahan Baku Biobriket dan Asap Cair" Kemendikbud. Bandung

[14] Najib, L dan Darsopuspito, S. 2012. "Karakterisasi Proses Gasifikasi Biomassa Tempurung Kelapa Sistem Downdraft Kontinyu dengan Variasi Perbandingan UdaraBahan Bakar (AFR) dan Ukuran Biomassa".

[15] Priyati, A dkk. 2014. "Karakteristik Suhu dan Produksi Gas Dengan Variasi Laju Input Udara Pada Proses Gasifikasi Tandan Kosong Kelapa Sawit Menggunakan Inverted Downdraft Gasifier". Pranolo, S. H. 2015, "Kinerja Pembangkit Listrik Dual-Fuel Kapasitas 5 kW Berbasis Gasifikasi Sekam Padi Berunggun Tetap”.

[16] Pranolo,S. H. 2010, "Potensi Penerapan Teknologi Gasifikasi Tongkol Jagung sebagai Sumber Energi Alternatif di Pedesaan”, Seminar Nasional Energi Terbarukan Indonesia di Universitas Jendral Sudirman, Purwokerto. 
[17] Rizkal A dan Sudarmanta B, 2016. "Karakterisasi Unjuk Kerja Diesel Engine Generator Set Sistem Dual Fuel Solar-Syngas Hasil Gasifikasi Briket Municipal Solid Waste (MSW) Secara Langsung".

[18] Susanto H. 2010, "Sekilas tentang Teknologi Gasifikasi".

[19] Saransi, A.U. 2018, "Penentuan Energi Bruto Dengan Bomb Calorimeter Toshniwal CCO1/M2". 